\title{
Violência, razão e cultura de paz
}

\section{Violence, reason and culture of peace}

\section{Uiolencia, razón y cultura de paz}

\section{Paulo César Nodari ${ }^{1}$}

Universidade de Caxias do Sul, Professor de Filosofia do Programa de Pós-Graduação em Filosofia

Resumo: $\bigcirc$ objetivo com este artigo foi refletir sobre a violência e a cultura da paz. Na primeira seção, à luz do pensamento de Eric Weil, trata-se de mostrar que o ser humano, como ser livre e racional, tem a responsabilidade de escolher entre a razão e a violência, considerando, no entanto, que tão somente a escolha pela razão estaria de acordo com o rumo de uma vida humana, de fato, livre e feliz. Na segunda seção, iluminados e inspirados pelas mensagens papais para a paz mundial por ocasião do primeiro dia de cada ano, iniciando com o Papa Paulo VI (1968) até nossos dias atuais com o Papa Francisco (2018), apresentam-se algumas proposições com o intento de oferecer possíveis pistas e caminhos de reflexão para o desenvolvimento progressivo de uma cultura de paz e de não violência.

Palavras-chave: Weil. Razão. Liberdade. Paz. Violência.

Abstract: The purpose of this article is to reflect on the violence and culture of peace. In the first section, in the light of Eric Weil's thought, it is a question of showing that the human being, as a free and rational being, has a responsibility to choose between reason and violence, considering, however, that only choice for reason would be in accordance with the course of a human life, in fact, free and happy. In the second section, illuminated and inspired by the papal messages for world peace on the first day of each year, beginning with Pope Paul VI (1968) to the present day Pope Francisco (2018), some propositions are presented with the attempt to offer possible clues and ways of reflection for the progressive development of a culture of peace and non-violence.

Keywords: Weil. Reason. Freedom. Peace. Violence.

Pós-Doutor em Filosofia pela Universidade de Bonn (Alemanha); Doutor em Filosofia pela Pontifícia Universidade Católica do Rio Grande do Sul. 
Resumen: El objetivo con este artículo fue reflexionar sobre la violencia y la cultura de la paz. En la primera sección, a la luz del pensamiento de Eric Weil, se trata de mostrar que el ser humano, como ser libre y racional, tiene la responsabilidad de elegir entre la razón y la violencia, considerando, sin embargo, que tan sólo la elección por la razón estaría de acuerdo con el rumbo de una vida humana, de hecho, libre y feliz. En la segunda sección, iluminados e inspirados por los mensajes papales para la paz mundial con ocasión del primer día de cada año, iniciando con el Papa Pablo VI (1968) hasta nuestros días actuales con el Papa Francisco (2018), se presentan algunas proposiciones con el intento de ofrecer posibles pistas y caminos de reflexión para el desarrollo progresivo de una cultura de paz y de no violencia.

Palabras clave: Weil. Razón. Libertad. Paz. Violencia.

\section{INTRODUÇÃO}

Paz e violência, o antônimo já há muito conhecido, não podem seguir o processo de caracterização e identificação naturalista, ou seja, a pessoa ou nasce dada à paz, ou, então, à violência. Embora seja muito discutida e controversa a questão acerca da tendência e da disposição do ser humano ou para a paz ou para a violência, tem-se a convicção de que o ponto mais importante para este ensaio reflexivo não está em discutir tais posicionamentos, porque haveria referenciais teóricos importantes de ambos os lados, o que se quer, no entanto, é argumentar a tese de que a paz e a violência dependem de muitos aspectos, dimensões e implicações, especialmente familiares, educacionais, culturais, sociais, políticos, econômicos, ambientais e, talvez, sem quaisquer preconceitos deterministas, naturalistas e hereditários.

propósito não é aprofundar tais questões referenciadas, antes, trazer à tona algumas luzes para fomentar e subsidiar possíveis discussões nos mais diversos âmbitos de interesse acerca do tema em torno da violência e da cultura de paz, denominada cultura de não violência ativa. Trata-se, pois, em 
um primeiro momento, de trazer à luz a concepção de Eric Weil ${ }^{2}$ acerca da possibilidade que todo ser humano tem de escolher entre dois caminhos, a saber, o da razão e o da violência. Após apresentar argumentos sustentadores da tese de que a escolha pela razão é a que ruma em direção ao caminho de encontro à verdadeira humanidade, em um segundo momento, quer-se, sobretudo da contribuição das mensagens dos papas, desde 1968 (do Papa Paulo VI) até 2018 (ao Papa Francisco), por ocasião do início de cada ano, primeiro dia do respectivo ano, trazer, ainda que de modo breve, algumas proposições educacionais importantes para a construção de uma cultura de paz e de não violência. Espera-se com essa estratégia não apenas se ater tão somente à discussão da violência e sua pluriversal forma de atuação e apresentação na sociedade, mas, acima de tudo, apresentar, por um lado, o complexo do problema da violência que atinge o ser humano e a sociedade, e, por outro, explicitar algumas, entre muitas outras, proposições importantes para serem trabalhadas com muito afinco e dedicação em todas as esferas e âmbitos da sociedade atual. Em outras palavras, quer-se sustentar que não basta e não é o escopo desta reflexão realizar uma radiografia e um mapeamento da violência nacional e internacional, ainda que as notícias, as informações e os dados estatísticos disponíveis e acessíveis a todos em espaço e domínio público, nos dias atuais, sejam alarmantes e possam vir, inclusive, a balançar a confiança e a esperança na humanidade enquanto tal, porque importante é tomar consistência e a tese de que a cultura de paz e de não violência ativa

\footnotetext{
2 Eric Weil nasceu aos 08 de junho de 1904 na Cidade alemã de Mecklenburg. De família com raízes judaicas, ele estudou filosofia e medicina em Berlim e Hamburgo. Em 1933, Eric Weil abandonou a Alemanha por motivos referentes ao início do Nazismo e foi para a França, permanecendo em um campo de prisioneiros durante toda a Segunda Guerra Mundial. Em 1950, ele iniciou seu período na docência. Lecionou nas Universidades de Lille e de Nice até o ano de sua morte, em 1977. Dentre suas obras destacam-se, sobremaneira: Lógica da filosofia (1950), Filosofia política (1956), Filosofia moral (1961), Problemas kantianos (1969) e Ensaios e conferências (1970 e 1971). Embora ele não seja ainda muito conhecido no Brasil, Eric Weil é um autor muito importante do Século XX por várias razões e motivações. Para a presente reflexão, a opção pelo referido autor ocorre por conta de suas brilhantes elucidações e contribuições a respeito de como se pode conceber e dar razões plausíveis para a elaboração reflexiva capaz de deliberar e escolher decididamente pela razão em detrimento da violência. E, nesse sentido, tão somente a partir da escolha pela razão é possível dar lugar à elaboração e à construção de uma cultura de paz e, por conseguinte, de não violência. Para este artigo, os dois textos referenciais de Eric Weil, aqui, utilizados são: Lógica da filosofia e Filosofia moral.
} 
precisa ser trabalhada em todas as instâncias e assumida por todas as pessoas, segmentos da sociedade civil e pelo Estado.

\section{LIBERDADE E RAZÃO}

Segundo Weil, o ser humano é capaz de razão e de violência, sendolhe possível escolher tanto uma quanto a outra. A escolha pela violência é o oposto à escolha pela razão, constituindo-se, pois, em atitude irracional, a qual ameaçaria o ser humano em sua própria humanidade. A escolha pela razão tem implicação direta na vida moral de cada ser humano, isto é, ele tem a missão de trabalhar pela paz, e, por conseguinte, contra a violência, buscando a felicidade, a qual, de acordo com a definição de Weil, é o exercício da razão, recusando a tudo o que o impediria de se tornar feliz e tudo o que o poderia desviar da vida racional. Livre e informado pela razão, o ser humano reconheceria sua própria humanidade. A primeira seção deste texto é organizada à luz da tese de Weil, segundo a qual a liberdade se constitui como a condição para a escolha de uma vida refletida, isto é, racional, e, consequentemente, uma vida não violenta, sendo, por conseguinte, a felicidade uma atividade da razão. À luz desse intento, enseja-se refletir sobre a ideia da escolha livre pela vida racional como caminho, diametralmente, oposto à violência, sobremaneira, de duas obras do autor referenciado, a saber: Lógica da filosofia (2012) e Filosofia moral (2011).

$\bigcirc$ pensamento proposto por Weil busca refletir sobre a questão da não violência. Já no início da obra Lógica da filosofia, ele procura compreender o ser humano e como seria possível ele vir a tornar-se violento. $\bigcirc$ ser humano é um ser capaz de razão e de violência, é, com efeito, "animal razoável" (WEIL, 2012, p. 22). Animal no sentido de ter em si uma tendência de agir ou com base nos instintos, tendências cegas e paixões, que, de certa forma, segundo Weil, não são racionais, ou razoavelmente, porque lhe é possível optar por uma via guiada pela razão. $\bigcirc$ ser humano enquanto ser de possibilidades pode optar agir guiado pela razão ou não, sabendo que a opção pela ação, que 
não a racional, torna-o violento, distante, em última análise, de sua própria humanidade. A missão, portanto, mais específica e própria do ser humano enquanto tal consistiria em ser capaz de escolher e agir racionalmente (WEIL, 2012, p. 22).

Violência, para Weil, está ligada a uma atitude do ser humano que não quer justificar sua vida racionalmente, confortando-se e acomodando-se com a expressão de seus sentimentos e desejos individuais. A violência representa a irracionalidade, o impedimento de o ser humano viver sua humanidade plenamente, uma vez que, de acordo com Weil (2012, p. 14), "[...] os homens não costumam dispor da razão e da linguagem razoável, mas devem delas dispor para serem homens plenamente." Por isso, a violência é uma atitude que contradiz a exigência de humanidade inerente ao ser humano, uma vez que a escolha pelo caminho da violência e não pela escolha da razão acaba por desumanizá-lo. Para que o ser humano se torne humano, realizado, e, por conseguinte, feliz, ele deve optar livremente pela razão e trabalhar incessantemente pela paz contra a violência se ele quiser ver realizar-se nele a vocação de ser humano enquanto tal.

A escolha entre a razão e a violência está intrinsecamente conectada à liberdade. $\bigcirc$ ser humano é capaz de razão e de violência, sendo-lhe possível escolher tanto uma quanto outra. A escolha pela violência é o oposto à escolha pela razão. É uma escolha livre, e, somente, o ser humano que escolheu a razão sabe e tem consciência de que é livre, de fato. "O homem pode escolher entre razão e não-razão, e aqui se evidencia que essa escolha em si jamais é uma escolha razoável, mas uma escolha livre." (WEIL, 2012, p. 86). Assim, a liberdade é anterior à escolha pela razão, sendo, pois, a escolha pela razão como que uma segunda natureza. $\bigcirc$ ser humano é livre antes mesmo de optar por uma ou outra possibilidade, isto é, de acordo com Weil (2012, p. 87), a razão é uma possibilidade do ser humano. Por ser uma possibilidade, sabe-se existir, no mínimo, outra possibilidade, isto é, pode-se escolher entre a razão e a violência. Logo, o caminho da razão não procederia como que de uma concepção de naturalização do processo ou de uma loteria natural, sendo dispensada a partir dos desejos arbitrários ou espúrios de algum ser ou entidade sobrenatural, mas, muito pelo contrário, tratando-se de um processo 
progressivo de orientação e formação de uma denominada segunda natureza, assim como a definiram tanto Kant quanto Hegel.

Ao renunciar a uma vida razoável, o ser humano submeter-se-ia à sua animalidade, às suas paixões e tendências cegas, renunciando à sua própria liberdade. É optando por uma vida justificada, uma vida racional, que o homem viverá sua liberdade e sua própria humanidade. Assim, a razão se apresenta como condição para a liberdade. Ela faz o ser humano libertarse de sua condição de animal irracional para assumir uma vida justificada e razoável. Dessa forma, ficam, pois, evidenciados dois modos de compreensão do termo liberdade: um referindo-se à possibilidade que o ser humano tem de escolha entre razão e violência, e outro, ao modo de libertar-se de sua condição de animal irracional, que o pode submeter às paixões e às tendências, denominadas por Weil (2012, p. 22), de cegas. Quando o ser humano opta pela razão, declarando-se razoável, ele expressa seu desejo de ser livre.

Nessa perspectiva, a filosofia tem o papel de auxiliar e possibilitar a reflexão com o intento de tornar o ser humano livre e capaz de justificar sua vida racionalmente. A filosofia, nesse sentido, é, para Weil, atividade da razão que nega a violência, uma vez que a filosofia enseja uma vida de reflexão, sendo muito razoável a busca por uma vida humana cada vez mais humanizada e alicerçada em valores fundamentais como a dignidade, a justiça, a felicidade e a liberdade, possibilitando superar, paulatina e progressivamente, o tanto mais quanto possível, a violência em suas mais diversas e sofisticadas formas (WEIL, 2012, p. 34). Sabe-se, portanto, por um lado, que a violência não tem uma solução mágica e definitiva, porque a possibilidade sempre iminente de queda ou de recaída na irracionalidade constitui-se em um risco ineliminável à escolha humana, e, por outro, que a paz não pode se basear em mera e falsa retórica e falácia de palavras bem aceitas, porque, atualmente, tem-se consciência de que não haverá paz se não houver, de fato, justiça e respeito sincero e verdadeiro a cada ser humano, a cada grupo étnico, a cada nação.

O ser humano que, em sua liberdade, busca a vida racional, torna-se ser razoável, ou então, sábio. A vida do ser humano razoável é expressa por Weil como sabedoria que se torna prática, isto é, a união da reflexão com a ação. $\bigcirc$ sábio é aquele que escolhe a vida razoável, e, por isso, sua ação no 
mundo será com base na razão, construindo relações de não violência. Por conseguinte, o ser humano que constrói sua vida alicerçada na escolha pela razão é um ser moral, livre e razoável. Sua opção pela razão torna-se opção pelo agir moral que se efetiva na decisão pela vida de não violência. Weil (201 l, p. 18) sustenta no livro Filosofia moral:

\begin{abstract}
O ser humano só é moral porque é, ao mesmo tempo, imoral: ele pode ser bom porque pode ser mau, e inversamente. Isso não quer dizer que as duas visões sejam falsas sob todos os aspectos; elas são verdadeiras, mas somente quando tomadas juntas [...] $\bigcirc$ homem não é naturalmente bom, mas também não é naturalmente mau; mais exatamente, quem possuísse uma ou outra dessas qualidades como se possui qualidades físicas não seria um homem, mas um animal ou um deus. $\bigcirc$ indivíduo deve ser conduzido ao bem, deve ser educado - e, portanto, deve poder sê-lo - para querer o bem e para evitar o mal; se abstrairmos dessa educação, ele não é nem bom nem mau, ele é, como se diz, amoral, não imoral, porque essa abstração o transforma em animal.
\end{abstract}

A moralidade é definida como capacidade de o ser humano ter uma consciência má ou boa. O ser humano pode ser bom ou mau, moral ou imoral. Assim, ele precisa ser conduzido, educado para o bem, para vir a tornase moral. Ou seja, inata ao homem é a capacidade que lhe advém inerente de poder discernir entre o bem e o mal, entre o lícito e o ilícito. É por essa capacidade que o ser humano é um ser moral, isto é, ele tem capacidade de separar o que e como deve agir de como não deve agir, atos que ele pode, com reflexão, aprovar ou desaprovar. Enquanto moral, o ser humano vive um sistema de regras, uma vez que sem regras reconhecidas ele viveria em sua condição natural. Segundo Weil (201 1, p. 19), o ser humano, enquanto natural, "[...] é violento, ele age cegamente, à maneira das forças naturais, determinado por elas e como elas, ele é dominado por suas tendências, instintos, necessidades." Porém, o ser humano, querendo assumir e enfrentar a difícil problematização da escolha, ou seja, de ter que escolher entre a possibilidade de ser bom ou mau, ele precisa tomar em conta a exigente realidade de que a escolha é a via de condução à vida livre e feliz. E como ele quer ser feliz, porque tem consciência de sua possibilidade de infelicidade, já que o caminho da 
felicidade e da realização não está, de antemão, garantido e realizado para ninguém, ele, enquanto um ser portador da capacidade intrínseca moral, quer libertar-se da condição animal e encontrar a felicidade. Escreve Weil (201 l, p. 41): "O homem moral (o homem que pretende ser moral) sabe que é animal, mas animal cuja animalidade, que tenta sempre negá-lo na sua moralidade, é negada por ele mesmo em favor da positividade de um sentido humano de sua existência animal."

O ser humano quer ser feliz. "Ele quer que a felicidade que ele busca seja verdadeiramente universal." (WEIL, 201 l, p. 48), na perspectiva de que ele quer a felicidade de todos. E essa vontade de universalidade, de felicidade de e para todos, interpretada como "natureza do ser humano", está ligada aos termos razão e liberdade. "O homem, enquanto visa à universalidade, é razoável; enquanto é capaz de universalidade, é liberdade: sendo capaz de razão, mas não sendo razão, ele é também capaz de optar contra a universalidade e contra a razão." (WEIL, 201 l, p. 52). Ele vive sua condição como ser livre. Está aberto à possibilidade, à escolha de uma vida refletida ou de uma vida de violência, própria de sua condição irracional. A razão e a violência só se separam da vida do ser humano quando este optar pela razão. Somente a escolha da razão dará ao homem a consciência do outro caminho, a violência. Só o ser humano que optou pela razão sabe que é livre, e escolhe livremente a razão, porque sabe que poderia ter optado pelo oposto da razão, a violência (WEIL, 201 l, p. 57).

Assim, a liberdade, própria de quem escolheu a vida razoável, é anterior à razão. "O homem só é livre à medida que se sabe livre." (WEIL, 2011 , p. 59). A liberdade somente é consciente para quem optou pela razão. A liberdade só existe para a razão. E é essa escolha que funda a razão. "Só um ser livre é capaz de buscar, vale dizer, de se separar de si mesmo para opor-se a si mesmo." (WEIL, 201 l, p. 59). A liberdade realiza-se e acontece, segundo Weil, não quando o ser humano se deixa submeter àquilo que o condiciona, enquanto animal afetado pelas paixões, pelas emoções, pelas tendências e pelo prazer, segundo Weil, mas quando ele se eleva de sua animalidade à sua humanidade. Dessa forma, o ser humano está diante de dois caminhos, ou escolhe uma vida moral, fundada na razão e na vontade razoável, que o levará à felicidade, ou escolhe o oposto, uma vida não refletida, guiado por 
seus instintos e desejos irracionais. Weil salienta ser a vontade razoável a guiar a escolha do ser humano.

homem é livre na medida em que não se submete, pura e simplesmente, imediatamente ao que condiciona, interior e exteriormente, o animal: assim, a vontade nada mais é do que o ser razoável e finito que pretende ser razoável na condição que é sua; ela não é uma faculdade do homem, ela é o próprio homem, que nela se torna homem, e que tornando-se homem razoável, descobre a si mesmo livre de uma liberdade que nada pode constranger: até mesmo a renúncia à liberdade permanece um ato livre. (WEIL, 201 l, p. 62).

Nessa linha de reflexão, a distinção entre desejo e vontade, em Weil, torna-se imprescindível, uma vez que o desejo estaria mais próximo à condição animal do ser humano, enquanto submissão aos seus instintos e tendências cegas, próprias de uma vida não refletida e irracional, ao passo que a vontade, por sua vez, estaria muito mais ligada à razão e à liberdade. A vontade de ser razoável é a não submissão àquilo que condicionaria o ser humano a deixarse guiar pelo animal irracional. "Vontade nada mais é do que o ser razoável e finito que pretende ser razoável na condição que é sua." (WEIL, 201 l, p. 63). A vontade razoável guia a escolha, ela é o ser razoável do ser humano que se descobre livre e, por sua vez, com uma liberdade que lhe é infinita. Nesse sentido, é importante dar-se conta de que o mundo em que se vive não dá garantia de realização e de felicidade. A felicidade precisa ser buscada e construída. Ou seja, o mundo no qual está o ser humano é o mundo que pode torná-lo feliz ou infeliz. Mesmo obtendo tudo o que desejou e deseja, o ser humano não tem a garantia de que será feliz, uma vez que a satisfação de um desejo gera, por sua vez, novos desejos e, assim, sucessiva e progressivamente. Em outras palavras, o ser humano precisa assumir o caminho de construção pessoal, caminho este da razão e do enfrentamento dos desejos e do medo, enquanto ser racional. $\bigcirc$ ser humano precisa assumir a sua autoconstrução. "A filosofia é sempre necessária e o homem é, para si mesmo, um ser verdadeiramente humano, porque quer sair de seu ser de homem." (WEIL, 2012, p. 241), enquanto animal com possibilidades de razão e de violência. 
Faz-se pertinente ao ser humano ter consciência de si e de suas possibilidades. Urge-lhe ter em mente que a consciência de quem ele é tem precedência com relação ao que tem e poderia ter. "A razão é liberdade que se determinou à razão, mas que só se compreende como razão por ter escolhido e por ser capaz de escolher." (WEIL, 201 l, p. 59). Em outras palavras, o ser humano só pode dizer-se livre quando se sabe livre, porque, por um lado, "[...] uma liberdade que não soubesse que é liberdade seria simples indeterminação, e só seria isso por relação a um ser livre e assim capaz de pôr a questão da determinação." (WEIL, 201 l, p. 59), e, porque, por outro lado: "[...] uma razão que não fosse livre seria uma vontade de universalidade incapaz de escolher e não se conheceria, pois só um ser livre é capaz de buscar, vale dizer de se separar de si mesmo para se opor a si mesmo." (WEIL, 201 l, p. 59). A razão não se funda em si mesma, ela se reconhece imersa na decisão pela razão. "A razão é liberdade que se determinou à razão, mas que só se compreende como razão por ter escolhido e por ser capaz de escolher." (WEIL, 201 l, p. 59). Em última análise, a razão reconhece que é incapaz de se fundar a si mesma (WEIL, 201 l, p. 59), nascendo e desenvolvendo-se de uma decisão pela própria razão, que não poderia, por conseguinte, ser imposta por outras razões, senão, tão somente, por uma decisão livre de exercício da razão que visa à felicidade.

O ser humano visa à felicidade. Ele quer ser feliz. A felicidade, para Weil, é o exercício da razão. É a conciliação do ser razoável consigo mesmo, porque felicidade é o exercício da razão. Não se trata de ser a razão como que um auxílio para chegar à felicidade, mas, antes, o próprio exercício da razão já é o caminho da felicidade. "Não é portanto com a ajuda da razão que o homem buscará a felicidade; a razão, o exercício da razão, a razão realizada pelo próprio homem em si mesmo é a felicidade." (WEIL, 201 l, p. 61). Assim, a felicidade é, por assim dizer, o exercício da razão, ciente de que o ser humano, para ser feliz, não busca eliminar ou abolir a infelicidade, uma vez que ele se reconhece como ser carente de desejos e necessidades, mas no exercício da liberdade racional. Em outras palavras, de acordo com Weil (201 1, p. 60): 


\begin{abstract}
O homem não ignora que ele é carente, cheio de necessidades e carregado de tarefas, exposto a todos os sofrimentos do animal, do ser finito que não se basta; mas, mesmo aceitando sua condição, ele quer ser feliz; ele pede - ele sabe agora que é a si próprio que ele o pede - uma felicidade que só dependa de si mesmo; o que ele busca não é a simples abolição da infelicidade e da divisão pelo aniquilamento de todo conteúdo, do eu e do mundo (cf. $\$ 9 \mathrm{c}$ ), mas uma felicidade positiva, um contentamento do qual ele possa estar seguro, um apaziguamento, senão permanente - pois o ser finito não poderia estar sem desejo ou necessidade em nenhum momento da sua existência empírica -, mas, em todo caso, um apaziguamento que a cada instante ele possa restituir a si mesmo ao reencontrar, quaisquer que sejam as circunstâncias exteriores, uma paz neste sentido imperdível.
\end{abstract}

A felicidade que o ser humano busca não é resultado de algo introjetado ou previamente estabelecido, mas, sim, totalmente interior, como uma coincidência, uma reconciliação do ser razoável consigo mesmo (WEIL, 2011, p. 61). O ser humano que se deixa mover totalmente pelos desejos, paixões, prazeres acaba dando primazia à sua condição de animal irracional. E em sendo assim, o ser humano estará na linha do contentamento, mas não da felicidade, que é mais do que simples contentamento. Para o animal dado à irracionalidade não há felicidade, tão somente contentamento, isto é, a realização dos prazeres e das paixões. A vontade do ser razoável de tender à felicidade e não ao mero contentamento só pode ser concebida no mundo da razão. A felicidade é fruto da paz interior, ou seja, está acima das vontades do animal irracional e é exigência do ser razoável. "É o ser humano enquanto razoável que quer ser feliz - e só ele pode conceber esse desejo, essencialmente não animal." (WEIL, 201 l, p. 61).

A felicidade é exercício da razão, na medida em que é razão realizada pelo próprio homem. $\bigcirc$ ser humano, como distingue Weil, tem o dever de recusar aquilo que ameaça sua própria humanidade e o torna infeliz. Logo, ele deve ser comprometido com a paz, afastando-se continuamente da violência. A não violência é um dever que o ser humano tem, assim como a felicidade o é. O ser humano não quer ser infeliz, nem quer que os outros o sejam. Seu desejo é por sua felicidade e a felicidade de todos, isto é, pela universalidade, sendo esta o fundamento da filosofia e regra da moral. A ação humana deve ter uma 
intenção de universalidade. É difícil de ser aprovada uma ação, cujo interesse seja tão somente particular, isto é, uma mera satisfação de desejos individuais. “É inadmissível toda ação que não seja dirigida à universalidade, à liberdade, à razão, à unidade que é a liberdade da razão universal [...]; é inadmissível toda ação cuja máxima seja a do ser particular, do desejo, do interesse particular." (WEIL, 201 1, p. 71 ).

O ser humano tem o dever de ser feliz, e ele só se torna moral à medida que cumpre o seu dever, dever de ser feliz. "O dever para consigo mesmo se determina como dever de ser feliz enquanto ser razoável." (WEIL, 201 1, p. 131). A busca da felicidade é dever do ser humano para consigo mesmo. Isso só se torna possível quando o ser humano consegue fazer predominar sobre seus instintos e seus desejos a razão. $\bigcirc$ ser humano será razoável e feliz na medida em que suas forças limitadas conseguirem fazer predominar a razão sobre suas tendências, instintos e paixões. Assim, o dever que o ser humano tem de ser feliz ocorre em razão de ele evitar a infelicidade, isto é, o outro da razão, a violência. O ser humano, no âmbito da filosofia moral, recusa escolher o que não o torna feliz, recusa o que pode desviá-lo da fonte inesgotável da paz interior e da construção histórica da via da não violência, uma vez que “[...] a razão, o exercício da razão, a razão realizada pelo próprio homem em si mesmo, é a felicidade." (WEIL, 201 l, p. 61).

O dever para consigo mesmo leva-o ao dever para com outrem. Pelo dever que cada um tem de realizar sua felicidade tem-se o dever para com os outros seres humanos. "A felicidade do ser razoável só se realiza, o dever para consigo só se torna concreto no cumprimento dos deveres do ser razoável para com outros seres humanos, igualmente finitos e razoáveis." (WEIL, 201 l, p. 143). É honroso trabalhar não somente para a própria satisfação, mas para a satisfação de todos. O dever para com o outro se fundamenta no dever de justiça. A justiça leva a tratar a outrem conforme cada um desejaria de ser tratado. $\bigcirc$ dever de felicidade que o ser humano tem para consigo e para com os outros caracteriza a vida informada pela moral. A moral informa a vida do ser humano, pois o guia pelo caminho da razão. Assim, a moral se torna concreta na vida do homem. O dever se torna natural na vida do homem moral. "O homem leva uma vida moral quando o cumprimento do seu dever se tornou 
natural para ele, um estilo de vida, uma atitude espontânea." (WEIL, 201 l, p. 198). Assim, a moral não é simplesmente discursiva, mas torna-se uma forma de vida em vista da felicidade. "A moral não é nada se não for vivida." (WEIL, 201 1, p. 227). A moral faz com que o ser humano assuma um compromisso para consigo mesmo e com o mundo, tornando, por conseguinte, a busca pela felicidade razoável. É um dever de responsabilidade que o ser humano tem diante de suas ações. $\bigcirc$ dever de agir moralmente é a atitude de quem aceita e quer o bem de si e de todos os outros. "Quem se contenta em querer o bem sem fazer o necessário para realizá-lo é talvez o pior inimigo da moral." (WEIL, 2011, p. 242).

A vida moral é guiada pela sabedoria prática que permite ao ser humano discernir, por meio da experiência e da reflexão, para chegar ao resultado por ele querido. A sabedoria prática, conceito resgatado da tradição grega, permite a compreensão de que a violência é um mal para si e para todos os outros homens. É amparado pela reflexão, pela razão e compreensão, e não por suas paixões e instintos que o homem fará suas escolhas, e a primeira delas será pela não violência. Assim, a escolha pela não violência se constitui o bem, a satisfação e a felicidade do ser humano moral.

A primeira e mais importante tarefa do indivíduo moral é se moralizar progressivamente, isto é, informar progressivamente suas paixões, interesses e tendências pela razão, de modo que transforme sua divisão interior de vontade de rebelião contra a razão em vontade de coincidência com ela. A moral quer informar a vida do indivíduo em sua totalidade, justamente porque quer informar o que não é moral e que, por isso mesmo, se refere à moral. Isso implica o trabalho constante do indivíduo, que sempre terá algo a submeter à razão [...] (PERINE, 1987, p. 246).

A vida do ser humano moral é sempre amparada pela filosofia. É ela que está associada à busca de felicidade do ser humano. A filosofia, como busca da reflexão e da compreensão, torna o ser humano livre, porque ele se deixou informar pela razão. "A liberdade é a razão: só o ser razoável, não arbitrário, não violento, é livre e sabe que é livre, ao viver segundo uma lei que é sua e que reconhece como estabelecida por ele mesmo, só o ser livre pode 
se querer e ser razoável." (WEIL, 201 1, p. 290). Ou seja, uma vida moral é uma vida conduzida pela razão. Uma vida moral é uma vida fundada no dever de ser feliz como ser razoável. A felicidade é produto de uma vida informada pela moral. $\bigcirc$ ser humano moral cumpre seus deveres morais, tendo como primeiro dever o de não violência. Ele é capaz de domínio de suas paixões e desejos. Torna-se feliz, porque ele tem uma vida informada pela razão. "A filosofia moral (a reflexão moral) informa a vida; faz parte da vida, nasceu nela, sem ela não seria nada e não existiria, assim como essa vida, na ausência da moral, não seria humana." (WEIL, 201 1, p. 293).

À luz da reflexão da primeira parte do artigo, chega-se à convicção de que a escolha que conduz à realização do ser humano, enquanto ser livre e racional, não tem outra opção de escolha senão pela opção pela paz e pela não violência, isto é, a escolha do caminho da razão. A seguir, na seção terceira, busca-se apresentar algumas proposições educacionais importantes para a construção e desenvolvimento da cultura de paz.

\section{EDUCAÇÃO E CULTURA DE PAZ}

Esta segunda parte da reflexão não tem outro escopo senão o de fomentar a importância da convivência cidadã responsável de todos nós, homens e mulheres, peregrinos e itinerantes, neste Planeta, denominado Terra, a qual, nós, há muito tempo, descobrimos ser esférica, ter limites, "obrigandonos", por conseguinte, a aprender a lição de viver e conviver uns com os outros, lembrando-nos, contínua e progressivamente, que as diferenças não se constituem em razão para afastamento e exclusão, mas, muito pelo contrário, movimento de aproximação e convivência cidadã e responsável. Portanto, não são as diferenças que afastam e excluem as pessoas e ocasionam injustiças e as mais diferentes formas de violência, porém, entre outras causas, por um lado, as desigualdades abissais e intransponíveis entre ricos e pobres, entre os considerados "agraciados" e "desgraçados", respectivamente, denominados de os bons e os maus, permanecendo e sendo os intitulados de "desgraçados", 
taxativamente, postos à marginalidade de uma vida digna e em condições razoáveis de vida humanizada, e, por outro lado, as diferentes formas de intolerâncias, sejam elas culturais, sociais, políticas ou religiosas, os mais esdrúxulos tipos de maniqueísmos, de fundamentalismos, os mais absurdos projetos eugênicos de limpeza étnica e as mais controversas maneiras de fomentar o medo e o ódio, etc. Desse olhar perspectivo de fundo, pretendese, a seguir, traçar algumas proposições imprescindíveis acerca da tarefa da educação, de cunho formal ou informal, de dimensões tanto socioambiental, quanto político-cultural, de abrangência regional e nacional, como também internacional, cuja finalidade principal é fomentar o desenvolvimento e o progresso humano, fundamentados no direito e na justiça, desencadeandose, por meio de um processo dialógico pacífico de espectro cosmopolita, a construção e a constituição de uma convivência cidadã responsável, à luz de alguns valores sabendo-os, simultaneamente, já velhos e sempre novos, a saber, a verdade, a justiça, a liberdade e o amor.

A paz não é simplesmente ausência de guerra e não é um conceito estático, mas dinâmico, entendido como comportamento e como acontecimento a ser instaurado e construído. A paz é um processo progressivo, ainda que inatingível em sua plenitude. A paz não é, por conseguinte, um conceito estático. Não é simplesmente ausência de guerra, pois nenhuma paz está ao abrigo de toda a ameaça de guerra. É um processo dialógico e não violento de respeito e construção coletiva. É a capacidade de instauração do diálogo incansável. Significa dizer que trabalhar pela paz implica engajamento, esforço, sacrifício. É compromisso inadiável de cada um e de todos. É a capacidade de assumir com responsabilidade os conflitos existentes e emergentes, buscando resolvêlos sem causar mais violência. Significa assumir com convicção e paixão a educação como possibilidade de instauração da paz. Já dizia o Papa Paulo VI por ocasião da instauração da mensagem para a celebração do I dia mundial da paz a ser celebrado todos os anos no primeiro dia de janeiro de cada ano, desde o ano 1968:

A Paz funda-se subjetivamente num espírito novo que há de animar a convivência dos povos, num novo modo de pensar o homem os seus deveres e o seu destino. Um lon- 
go caminho resta ainda a percorrer, para tornar universal e operante esta mentalidade: uma nova pedagogia deve educar as novas gerações para o respeito mútuo das nações, para a fraternidade dos povos e para a colaboração das pessoas entre si, e, tudo isto afinal; em vista do próprio progresso e desenvolvimento. Os organismos internacionais, instituidor para este fim, devem ser sustentados por todos, melhor conhecidos, dotados de autoridade e de meios idóneos para a sua grande missão. $\bigcirc$ "Dia da Paz" deve tributar honras a estas instituições, emoldurar de prestígio a sua obra e rodeá-las de confiança e daquela expectativa que servem a manter nelas, sempre vigilante o sentido das suas gravíssimas responsabilidades, e forte a consciência do mandato que lhes foi confiado. (VATICA$\mathrm{NO}, 1968)$.

A paz é processo educativo progressivo ainda que se saiba que nunca pode ser atingido por completo. Educar é sempre um desafio. Educar para a paz agrega ao desafio um comprometimento com uma sociedade mais justa, igualitária e responsável. Educar necessita desempenhar um papel fundamental no intuito de possibilitar a sensibilização de todos para as questões como a justiça e a paz, contribuindo não somente para a percepção, porém, principalmente, à formação de uma consciência de paz. Trata-se não apenas de conscientizar estudantes, mas, também, professores, pais, famílias e toda a comunidade, chamando-os para um compromisso, uma postura e uma prática de atitude de paz. A educação é uma das pedras fundamentais sobre a qual se assenta uma nação forte, competente, criativa e democrática. Apesar de diversas autoridades não enxergarem isso, não é possível simplesmente transferir só às autoridades aquilo que é de competência de cada um. Culpar os governos ou os meios de comunicação talvez seja um ato de comodismo e se trata de uma postura insuficiente. Educar para uma cultura de paz no século XXI consolida as reivindicações feitas por diversas culturas no decorrer dos séculos. Não se fala de uma paz mascarada, nem simbólica e tampouco bonita só no papel ou nos cartazes em datas comemorativas. Fala-se de uma paz efetiva. Faz-se menção a uma paz para toda humanidade, que rogue por justiça e compaixão. Mudar a realidade de conflitos e de julgamentos apressados e fechados ao diálogo e de agressões à possibilidade da formação de uma cultura da paz, sabendo, no entanto, que a cultura da não violência exige compromisso e envolvimento sistemático de todas as pessoas, comunidades, 
instituições e nações. Assim, quem sabe, episódios de violência que atingiram e atingem famílias, escolas e instituições possam comprometer a todos na busca de soluções plausíveis. Tais acontecimentos revelam a realidade a ser pensada por todos nós e por todos os segmentos da sociedade. Embora seja sumamente importante a busca tanto do julgamento quanto da proteção das vítimas e dos agressores em casos de agressão e violência, acredita-se não ser suficiente buscar os culpados de quaisquer gestos e atos de agressão e violência. Temse que pensar uma sociedade propícia à convivência. Precisa-se aprender a conviver. Um caminho muito sensato é assumir com seriedade o compromisso e a responsabilidade tanto pessoal quanto social da formação e da construção de uma sociedade alicerçada sobre a sabedoria da convivência, do diálogo e do respeito. João Paulo II, por ocasião da XXXIV mensagem para o dia mundial da paz em 2001, no número 10, assim se expressou:

O diálogo leva a reconhecer a riqueza da diversidade e predispõe os ânimos para a recíproca aceitação, em ordem a uma autêntica colaboração, de acordo com a primordial vocação à unidade de toda a família humana. Como tal, o diálogo é um instrumento sublime para realizar a civilização do amor e da paz, que o meu venerando predecessor Papa Paulo VI indicou como o ideal que deve inspirar a vida cultural, social, política e económica do nosso tempo. No início do terceiro milénio, é urgente propor novamente o caminho do diálogo a um mundo atribulado por demasiados conflitos e violências, por vezes desanimado e incapaz de perscrutar os horizontes da esperança e da paz. (VATICANO, 2001).

A paz é conversão das estruturas, mas especialmente das pessoas. A busca da cultura de paz não é só uma questão de estruturas. É, acima de tudo, uma questão de pessoas. Ou seja, estruturas e mecanismos jurídicos, políticos e econômicos são necessários, mas gestos de paz nascem da vida de pessoas que cultivam constantemente no próprio espírito atitudes de paz. Gestos de paz criam uma tradição e uma cultura de paz. É necessário aprender a ser pessoa de paz, dominando os impulsos de agressão, de vingança e de violência. E, além disso, enquanto cidadãos, cada um precisa assumir uma postura de portador e educador para a paz. Não existem receitas, nem manuais. Existem 
a possibilidade e a necessidade de ações a favor da paz. Pequenos gestos e pequenas atitudes podem tornar cada um e todos interlocutores e protagonistas da paz. No dia a dia, normalmente, cada um participa em distintos grupos, estejam eles constituídos por relação de afeto e amizade, ou, então, por relação de trabalho e interesse. Eis como se expressou o Papa João Paulo II por ocasião da mensagem do XXXVI dia da Paz, 01 de janeiro de 2003, número 09:

Vendo bem as coisas, tem-se de reconhecer que a paz não é uma questão tanto de estruturas como sobretudo de pessoas. Sem dúvida que as estruturas e os mecanismos de paz - jurídicos, políticos e económicos - são necessários e muitas vezes felizmente existem; mas constituem apenas o fruto da sabedoria e da experiência acumulada, ao longo da história, pelos inumeráveis gestos de paz, realizados por homens e mulheres que souberam esperar, sem nunca ceder ao desânimo. Gestos de paz nascem da vida de pessoas que cultivam constantemente no próprio espírito atitudes de paz; são fruto da mente e do coração de «obreiros da paz» (cf. Mt 5, 9). Gestos de paz são possíveis quando as pessoas têm em grande apreço a dimensão comunitária da vida, podendo assim perceber o significado e as consequências que certos acontecimentos têm para a sua própria comunidade e para o mundo inteiro. Gestos de paz criam uma tradição e uma cultura de paz. (VATICANO, 2003).

A paz é um processo de construção dialógica e de respeito às diferenças. Tanto o construir quanto o vivenciar a paz não são como se fosse apropriação de um objeto. Ela é, muito mais, como algo, uma força vital que move e deve ser assumida e construída por nós. É uma capacidade que permite pensar a diversidade constitutiva dos povos e na unidade da diversidade das culturas, povos e nações. Em diferentes esferas, sejam elas socioculturais, sejam escolares, a paz pode ser considerada de diversas maneiras e refletida em diferentes formas de agir. Os líderes nessas instâncias agem distintamente, porque especialmente na diversidade é que a paz se faz presente. A paz não é um estado dado, mas algo a ser instaurado e construído por nós, e da qual não se é cliente ou seus beneficiários. Urge tornar-se sujeito de construção histórica. Essa postura perpassa todas as organizações, sejam quais forem, militares, sociais, políticas, religiosas, educacionais. $\bigcirc$ que auxilia no embate 
desses grupos e instituições não é o grau e a escala de poder que os determina, mas o diálogo incansável pela construção de uma cultura de paz que permita que a diversidade faça parte e enriqueça o todo. A construção de uma cultura de paz necessita de um exercício generoso de diálogo entre os seres de forma individual e coletiva e, dessa forma, a paz é sempre vista como uma construção de todos e não um simples decreto deste ou daquele poder. Exatamente por residir na heterogeneidade, ela permite pensar em uma cultura de paz, inclusive falar de culturas de paz. Portanto, sendo um processo infindo devemos refletir e construir a paz. Como permanente possibilidade de efetuação, a paz ao mesmo tempo se realiza e se perde, se revela e se esconde, mostrando-se na sua eventualidade, imperfeição e incompletude. Afirmou o Papa João Paulo II, por ocasião da XXXIV mensagem para o dia mundial da paz em 2001, no número 20:

Para edificar a civilização do amor, o diálogo entre as culturas deve procurar remover todo o egoísmo etnocêntrico para conjugar o cuidado pela liberdade própria com a compreensão dos outros e o respeito da diversidade. Para isso, é fundamental a responsabilidade da educação. Esta deve transmitir aos sujeitos a consciência das suas próprias raízes e proporcionar pontos de referência que lhes permitam definir a sua colocação pessoal no mundo. Ao mesmo tempo deve empenhar-se no ensino do respeito pelas outras culturas. É preciso estender o olhar para além da experiência individual imediata e aceitar as diferenças, descobrindo a riqueza da história dos outros e dos seus valores.

$\bigcirc$ conhecimento das outras culturas, feito com o devido sentido crítico e com sólidos pontos de referência ética, conduz a uma maior consciência dos valores e limites presentes na nossa própria cultura e, simultaneamente, mostra a existência duma herança comum a todo o género humano. Em virtude precisamente desta abertura de horizontes, a educação tem uma função particular na construção dum mundo mais solidário e pacífico. Ela pode contribuir para a consolidação daquele humanismo integral, aberto à dimensão ética e religiosa, que sabe atribuir a devida importância ao conhecimento e apreço das culturas e dos valores espirituais das diversas civilizações. (VATICANO, 2001). 
O diálogo busca trabalhar os conflitos sem criar mais violência, mas, sim, convivência. Enquanto protagonistas e interlocutores de paz, na busca e na construção de uma cultura de paz e da resolução e superação de conflitos, têm-se condições de contribuir para a superação das várias formas de violência e injustiça. Sendo o conflito e os desafios constitutivos da existência humana, a linguagem dialógica se torna, por excelência, o meio, a instância, talvez, o "mundo" privilegiado para a busca da paz. Na e pela linguagem a paz encontra espaço propício para se desenvolver enquanto âmbito e espaço argumentativo. Trata-se de privilegiar um amplo e aberto processo democrático, reflexivo e crítico. Esse espaço argumentativo assume uma dupla dimensão. Por um lado, é preciso criticar todas as formas de violência na tentativa de buscar critérios de análise e compreensão de como ocorre a produção e a expressão da violência na sociedade, construindo, por sua vez, um sistema capaz de vigilância e de controle a tais mecanismos de produção. Por outro lado, urge pensar e efetivar alternativas e possibilidades que se concentrem no planejamento, detalhamento e caracterização de uma agenda e de um projeto de paz arrojado, ainda que seja um exercício contínuo de imaginação utópica, isto é, enquanto busca progressiva de um horizonte capaz de firmar projetos viáveis de construção de paz. O Papa Bento XVI, por ocasião do dia mundial da paz de 01 de janeiro de 2008, no número 14, expressou-se no sentido de convocar a todos os governos e responsáveis e a todas as pessoas para assumirem a busca da coexistência harmoniosa para o bem e o fim comum de todos os cidadãos e cidadãs mundiais.

A humanidade vive hoje, infelizmente, grandes divisões e fortes conflitos que lançam densas sombras sobre o seu futuro. Temos vastas áreas do planeta envolvidas em tensões crescentes, enquanto o perigo de se multiplicarem os países detentores de armas nucleares cria motivadas apreensões em toda a pessoa responsável. Há ainda muitas guerras civis no continente africano, embora também se tenham registado em vários dos seus países progressos na liberdade e na democracia. $\bigcirc$ Médio Oriente continua a ser teatro de conflitos e atentados, que não deixam de influenciar nações e regiões limítrofes com o risco de arrastá-las na espiral da violência. A nível mais geral, há que registar, com tristeza, um número maior de Estados envolvidos na corrida aos armamentos: temos até nações em vias de desenvolvimento que destinam uma quota importante 
do seu magro produto interno para a compra de armas. Neste funesto comércio, são muitas as responsabilidades: há os países do mundo industrialmente desenvolvido que arrecadam avultados lucros da venda de armas e temos as oligarquias reinantes em muitos países pobres que pretendem reforçar a sua posição com a aquisição de armas cada vez mais sofisticadas. Em tempos tão difíceis, é verdadeiramente necessária a mobilização de todas as pessoas de boa vontade para se encontrar acordos concretos que visem uma eficaz desmilitarização, sobretudo no campo das armas nucleares. Nesta fase em que o processo de não proliferação nuclear marca passo, sinto-me no dever de exortar as Autoridades a retomarem, com mais firme determinação, as conversações em ordem ao desmantelamento progressivo e concordado das armas nucleares existentes. Ao renovar este apelo, sei que dou voz a um desejo compartilhado por quantos têm a peito o futuro da humanidade. (VATICANO, 2008).

A cultura da paz é definida como um conjunto de valores, atitudes, condutas e estilos de vida que rejeitam toda forma de violência. Não basta simplesmente pensar que a cultura de paz se constituiria na ausência de conflitos e de guerras. Não é apenas o equilíbrio entre as forças dominantes. Não é o recíproco equilíbrio entre os proprietários dos armamentos para dissuadi-los do risco de sua utilização. Não basta visar ao fim dos conflitos e da violência direta, ou seja, da denominada paz negativa. Antes, pelo contrário, faz-se urgente a implementação da paz positiva, isto é, aprender e ensinar que a paz é fruto cultural, fruto da dispensa de muito esforço e de muito trabalho contínuos. É a busca do estofo político-cultural e socioambiental nacional e internacional favorável à eliminação, constante e progressivamente, tanto das causas, quanto dos efeitos da violência estrutural, tendo consciência de que não há receitas prontas, fáceis e definitivas. Por isso, segundo o Papa Francisco, de acordo com sua mensagem para o dia mundial da paz em 2017, no número 6, trabalha a ideia de que a construção da paz por meio da não violência ativa é um dos meios propícios e elementares não só da Igreja, mas de todas as instituições que buscam a convivência pacífica e responsável para todas as pessoas. A violência não é o remédio para o mundo dilacerado. Faz-se urgente um programa de não violência, porque, já em 1968, Paulo VI, na primeira mensagem para o dia mundial da paz, salientava ser a paz a única e a verdadeira linha para o 
progresso humano. Nesse sentido, sublinhou o Papa Francisco na mensagem para o primeiro dia de janeiro de 2017:

\begin{abstract}
Este é um programa e um desafio também para os líderes políticos e religiosos, para os responsáveis das instituições internacionais e os dirigentes das empresas e dos meios de comunicação social de todo o mundo: aplicar as Bem-aventuranças na forma como exercem as suas responsabilidades. É um desafio a construir a sociedade, a comunidade ou a empresa de que são responsáveis com o estilo dos obreiros da paz; a dar provas de misericórdia, recusando-se a descartar as pessoas, danificar o meio ambiente e querer vencer a todo o custo. Isto requer a disponibilidade para «suportar o conflito, resolvê-lo e transformá-lo no elo de ligação de um novo processo».[20]. Agir desta forma significa escolher a solidariedade como estilo para fazer a história e construir a amizade social. A não-violência ativa é uma forma de mostrar que a unidade é, verdadeiramente, mais forte e fecunda do que o conflito. No mundo, tudo está intimamente ligado. [21]. Claro, é possível que as diferenças gerem atritos: enfrentemo-los de forma construtiva e não-violenta, de modo que "as tensões e os opostos [possam] alcançar uma unidade multifacetada que gera nova vida», conservando "as preciosas potencialidades das polaridades em contraste». [22]. (VATICANO, 2017).
\end{abstract}

Passar da cultura da voracidade e do consumo para uma cultura de cooperação e de responsabilidade pelo Planeta. Nessa perspectiva, será possível olhar a violência e a guerra não mais como a última palavra sobre a realidade, uma espécie de sentença a que todos estão condenados. A paz é mais forte que a violência. Urge dar à paz contornos melhor definidos e ousados. A paz não é algo acabado ou um objeto do qual detemos a posse como se fosse uma espécie de mercadoria. A paz é muito mais um acontecimento. É uma atitude. É um comportamento. É um processo com o qual devemos nos engajar. É um projeto de ação de forma a incluir o corpo social, político e econômico numa ampla e solidária visão de paz. $\bigcirc$ projeto poderá virar movimento em curso, muito mais do que uma simples meta a ser alcançada estática e individualmente. Por isso, não podemos aceitar passivamente a violência. Pelo contrário, temos de nos indignar diante de gestos e atitudes de agressão e violência, sejam eles cometidos por quem for. É compromisso inadiável de cada um e de todos. É a capacidade de assumir com responsabilidade os conflitos 
existentes e emergentes, buscando resolvê-los sem causar mais violência. E isso significa assumir com convicção e paixão a educação como possibilidade de instauração da paz. Afinal, cada cidadão é, de um modo ou de outro, um potencial educador e guardião da paz. Para tanto, cada um precisará assumir com convicção que trabalhar pela paz e pela convivência cidadã e responsável exige engajamento, esforço, sacrifício, compromisso no combate ao ódio, aos maniqueísmos, à intolerância e à ideia de inimigo, ao medo, aos fundamentalismos, às mentiras, à corrupção, à dominação. Sabe-se não ser uma missão fácil, ainda assim, não impossível. Veja-se, por exemplo, não findado o primeiro quartel do século XXI, o caminho que ainda se tem a percorrer, tanto em nível nacional, quanto internacional, no que diz respeito aos oito objetivos traçados pela Organização das Nações Unidas (ONU), no ano 2000, a saber:
a) acabar com a fome e a miséria;
b) educação básica de qualidade para todos;
c) igualdade entre os sexos e valorização da mulher;
d) reduzir a mortalidade infantil;
e) melhorar a saúde das gestantes;
f) combater a AIDS, a malária e outras doenças;
g) qualidade de vida e respeito ao ambiente;
h) todo mundo trabalhando pelo desenvolvimento.

E se não bastasse a lembrança dos oito objetivos explicitados, e tão infimamente trabalhados e efetivados, especialmente, no Brasil, poder-se-ia lembrar, também, a Agenda 2030 da Organização das Nações Unidas e sua difícil e complexa possibilidade de efetivação. Eis o elenco dos 17 objetivos:

a) acabar com a pobreza em todas as suas formas, em todos os lugares; 
b) acabar com a fome, alcançar a segurança alimentar e melhoria da nutrição e promover a agricultura sustentável;

C) assegurar uma vida saudável e promover o bem-estar para todos, em todas as idades;

d) assegurar a educação inclusiva e equitativa e de qualidade, e promover oportunidades de aprendizagem ao longo da vida para todos;

e) alcançar a igualdade de gênero e empoderar todas as mulheres e meninas;

f) assegurar a disponibilidade e gestão sustentável da água e saneamento para todos;

g) assegurar o acesso confiável, sustentável, moderno e a preço acessível à energia para todos;

h) promover o crescimento econômico sustentado, inclusivo e sustentável, emprego pleno e produtivo e trabalho decente para todos;

i) construir infraestruturas resilientes, promover a industrialização inclusiva e sustentável e fomentar a inovação;

j) reduzir a desigualdade dentro dos países e entre eles;

k) tornar as cidades e os assentamentos humanos inclusivos, seguros, resilientes e sustentáveis;

1) assegurar padrões de produção e de consumo sustentáveis;

m) tomar medidas urgentes para combater a mudança do clima e seus impactos;

n) conservação e uso sustentável dos oceanos, dos mares e dos recursos marinhos para o desenvolvimento sustentável;

o) proteger, recuperar e promover o uso sustentável dos ecossistemas terrestres, gerir de forma sustentável as florestas, combater a 
desertificação, deter e reverter a degradação da terra e deter a perda de biodiversidade;

p) promover sociedades pacíficas einclusivas para o desenvolvimento sustentável, proporcionar o acesso à justiça para todos e construir instituições eficazes, responsáveis e inclusivas em todos os níveis;

q) fortalecer os meios de implementação e revitalizar a parceria global para o desenvolvimento sustentável.

Muito embora não se tenha o propósito de trabalhar pormenorizadamente tais objetivos, intenta-se, com essas breves informações, tão somente constatar o longo caminho que ainda resta a percorrer. Trata-se de conceber um desenvolvimento sustentável com vistas à solidariedade entre as nações, entre os povos e entre as gerações, ou seja, não basta apenas defender a ideia de ser necessário se preocupar com as gerações futuras, é preciso ter consciência de que é a própria dignidade humana que está em jogo, em última análise, ao se tratar da crise ecológica mundial, referenciada como crise integral. O Papa Francisco, por sua vez, salienta, na Encíclica Laudato Si', n. 159, a respeito da urgência da missão:

A noção de bem comum engloba também as gerações futuras. As crises econômicas internacionais mostraram, de forma atroz, os efeitos nocivos que traz consigo o desconhecimento de um destino comum, do qual não podem ser excluídos aqueles que virão depois de nós. Já não se pode falar de desenvolvimento sustentável sem uma solidariedade intergeracional. Quando pensamos na situação em que se deixa o planeta às gerações futuras, entramos em outra lógica: a do dom gratuito, que recebemos e comunicamos. Se a terra nos é dada, não podemos pensar apenas a partir de um critério utilitarista de eficiência e produtividade para lucro individual. Não estamos falando de uma atitude opcional, mas de uma questão essencial de justiça, pois a terra que recebemos pertence também àqueles que hão de vir. (VATICANO, 2015, p. 95).

A cultura de paz não aceita que seja com indiferença e omissão tratado o problema dos migrantes e refugiados e requer consequentemente a 
responsabilidade cidadã cosmopolita. Não obstante se saiba que o ser humano é caracterizado como itinerante e peregrino, não se está tratando dessa dimensão. Trata-se, muito mais, de considerar o Planeta como a casa comum de todos e não de quem tem mais posses, dinheiro e poder, lembrando o que Kant sublinha no texto de À paz perpétua, em seu segundo artigo definitivo, a saber, que cada ser humano tem o direito de hospitalidade, isto é, tem o direito de ser bem acolhido. Evidentemente, do ponto de vista do direito internacional, ou seja, das relações diplomáticas internacionais, não é tão simples nos dias atuais. Mas isso não significa afirmar e aceitar a tese de que não seja possível, uma vez mais, o esforço e o empenho por parte de todas as nações, cuja finalidade seja enfrentar com responsabilidade cosmopolita o desafio das atuais migrações, muitas vezes, como a única possibilidade de esperança e de futuro. A cultura da não violência ativa exige enfrentar com responsabilidade os eminentes conflitos dos migrantes e refugiados. Não basta o discurso da sensibilização e da solidariedade reflexiva a respeito do sofrimento dos outros, ainda que muito importante. Faz-se urgente encontrar e viabilizar propostas de caminhos capazes de assegurar os direitos fundamentais e o desenvolvimento harmônico, e, sobremaneira, o progresso de atitude e espírito humanitário. Na mensagem para o $51^{\circ}$ dia da paz, em 01 de janeiro de 2018, o Papa Francisco, lembrando a sequência de guerras, conflitos e genocídios, de limpezas étnicas, do século XX, convida a olhar e constatar que, infelizmente, neste primeiro quartel de século XXI, ainda se constatam infindáveis conflitos armados e tantas outras formas de violência, deslocando pessoas, grupos e até mesmo populações, no interior das fronteiras nacionais e além delas, na busca de uma vida melhor e no intento de deixar para trás o desespero de presente incerto e de um futuro impossível de construir. É nessa linha de pensamento que o Papa Francisco lança um olhar e toca em um dos pontos nevrálgicos da atualidade, a saber, as causas das frequentes e insistentes migrações e o respectivo acolhimento dado pelos países aos migrantes, seja como migrantes em busca de novas oportunidades de vida, seja como refugiados, como asilados, ou vítimas do tráfico humano, lembrando que se trata de uma das formas de violência, sobretudo quando não se olha e não se assume tal realidade com responsabilidade e com intenção de auxiliar na melhora das condições de convivência internacional. Não é possível a atitude de quem olha 
para a globalização e a internacionalização da economia de mercados e não para a globalização da solidariedade e da paz. O Papa Francisco, como líder da Igreja Católica, e, enquanto proeminente líder político no cenário político internacional, com atitude de muita responsabilidade, escreveu a respeito de um propósito urgente da comunidade política internacional:

\begin{abstract}
Almejo do fundo do coração que seja este espírito a animar o processo que, no decurso de 2018, levará à definição e aprovação por parte das Nações Unidas de dois pactos globais: um para migrações seguras, ordenadas e regulares, outro referido aos refugiados. Enquanto acordos partilhados a nível global, estes pactos representarão um quadro de referência para propostas políticas e medidas práticas. Por isso, é importante que sejam inspirados por sentimentos de compaixão, clarividência e coragem, de modo a aproveitar todas as ocasiões para fazer avançar a construção da paz: só assim o necessário realismo da política internacional não se tornará uma capitulação ao cinismo e à globalização da indiferença. (VATICANO, 2018).
\end{abstract}

\title{
4 CONCLUSÃO
}

Por fim, para tecer uma breve consideração final, à luz da mensagem para o dia da paz, em 2012, do Papa Bento XVI, lembra-se que para ser artífice de paz, urge educar toda pessoa para a compaixão, à solidariedade, à colaboração, à fraternidade. É preciso sentir-se ativo dentro da comunidade de vida e solícito em despertar a consciência para as questões nacionais e internacionais, sobretudo no que diz respeito à distribuição da riqueza, à promoção do crescimento de cooperação para o desenvolvimento harmônico e à resolução dos conflitos. Afirmou o Papa Bento XVI, na referida mensagem, em seu número 6: "A paz para todos nasce da justiça de cada um, e ninguém pode subtrair-se a este compromisso essencial de promover a justiça segundo as respectivas competências e responsabilidades." Visualiza-se, pois, uma urgência premente e, por assim dizer, inadiável, nos dias atuais, de propor e promover uma pedagogia de paz e de não violência ativa, e seja ela capaz de desenvolver em cada pessoa pensamentos, palavras, gestos, atitudes de paz, 
porque, com uma tal postura, pode-se, paulatina e progressivamente, fomentar e desenvolver nas pessoas, nos grupos, nas comunidades e nas nações uma mentalidade e uma cultura de paz, uma atmosfera de respeito, de honestidade e de cordialidade. É preciso, por isso, viver mais de benevolência e de diálogo que de mera tolerância. É fundamental viver mais de justiça que de mera lógica da retribuição coativa. É urgente mais perdão e menos vingança. É preciso renunciar à logica do consumismo exacerbado e assumir mais a solidariedade, a compaixão e o serviço em favor do bem comum. É imprescindível buscar mais cooperação que competitividade. É necessário superar a diabólica lógica da indiferença, da insensibilidade, do fechamento em si mesmo, do individualismo para buscar mais a proximidade, a compaixão, o serviço, a perseverança e a solidariedade.

\section{REFERÊNCIAS}

ORGANIZAÇÃO DAS NAÇÕES UNIDAS. Transformando Nosso Mundo: A Agenda 2030 para o Desenvolvimento Sustentável. Disponível em: <https:// nacoesunidas.org/pos2015/agenda2030/>. Acesso em: 15 jan. 2018.

PAPA FRANCISCO. Carta Encíclica do Sumo Pontífice: Laudato Si'. Louvado sejas. Sobre o cuidado da casa comum. São Paulo: Paulus; Loyola, 2015.

PERINE, M. Filosofia e violência: sentido e intenção da filosofia de Eric Weil. São Paulo: Loyola, 2013.

VATICANO. Mensagem de Sua Santidade Bento XVI para a celebração do $41^{\circ}$ dia mundial da paz. 01 jan. 2008. Disponível em: <https:// w2.vatican.va/content/benedict-xvi/pt/messages/peace/documents/hf_ben-xvi_mes_20071208_xli-world-day-peace.html>. Acesso em: 15 jan. $20 \overline{1} 8$.

\section{VATICANO. Mensagem de Sua Santidade João Paulo II para a celebração} do XXXIV dia mundial da paz. 01 jan. 2001. Disponível em: <https://w2.vatican.va/content/john-paul-ii/pt/messages/peace/documents/ hf_jp-ii_mes_20001208_xxxiv-world-day-for-peace.html>. Acesso em: 15 jan. 2018.

VATICANO. Mensagem de Sua Santidade João Paulo II para a celebração do $36^{\circ}$ dia mundial da paz. 01 jan. 2003. Disponível em: <https:// w2.vatican.va/content/john-paul-ii/pt/messages/peace/documents/hf_jp-ii mes_20021217_xxxvi-world-day-for-peace.html>. Acesso em: 15 jan. 2018. 
VATICANO. Mensagem de Sua Santidade Paulo VI para a celebração do $1^{\circ}$ dia mundial da paz. 01 jan. 1968. Disponível em: <https://w2.vatican.va/ content/paul-vi/pt/messages/peace/documents/hf_p-vi_mes_19671208_i-world-day-for-peace.html>. Acesso em: 15 jan. 2018.

\section{VATICANO. Mensagem do Santo Padre Francisco para a celebração do} 50 dia mundial da paz. 01 jan. 2017. Disponível em: <https://w2.vatican. $\mathrm{va} /$ content/francesco/pt/messages/peace/documents/papa-francesco_20161208_messaggio-l-giornata-mondiale-pace-2017.html >. Acesso em: 15 jan. 2018.

\section{VATICANO. Mensagem do Santo Padre Francisco para a celebração do} 51 ${ }^{\circ}$ dia mundial da paz. 01 jan. 2018. Disponível em: <https://w2.vatican. $\mathrm{va} / \mathrm{content} / \mathrm{francesco} / \mathrm{pt} / \mathrm{messages} /$ peace/documents/papa-francesco_20171113_messaggio-5l giornatamondiale-pace2018.html>. Acesso em: 15 jan. 2018.

WEIL, E. Filosofia moral. São Paulo: É Realizações Editora, 2011.

WEIL, E. Lógica da filosofia. São Paulo: É Realizações Editora, 2012.

Recebido em:: 30 de janeiro de 2018 Aceito em:: 19 de março de 2018

Endereço para correspondência: Rua Francisco Getúlio Vargas, 1 130, 95070560, Caxias do Sul, Rio Grande do Sul, Brasil; paulocesarnodari@hotmail. $\mathrm{com}$ 
